\title{
Reduction of Hospital Physicians' Workflow Interruptions: A Controlled Unit-Based Intervention Study
}

\author{
Matthias Weigl ${ }^{*}$, Severin Hornung ${ }^{2}$, Jürgen Glaser ${ }^{13}$, Peter Angerer ${ }^{4}$ \\ ${ }^{1}$ Institute and Outpatient Clinic for Occupational, Social, and Environmental \\ Medicine, Ludwig-Maximilians-University Munich, Germany \\ ${ }^{2}$ Department of Management and Marketing, The Hong Kong Polytechnic University, \\ Hong Kong, SAR China \\ ${ }^{3}$ Institute of Psychology, University of Innsbruck, Austria \\ ${ }^{4}$ Institute for Occupational and Social Medicine, Heinrich-Heine University \\ Düsseldorf, Germany
}

Submitted November 2011. Accepted for publication July 2012.

\begin{abstract}
Highly interruptive clinical environments may cause work stress and suboptimal clinical care. This study features an intervention to reduce workflow interruptions by re-designing work and organizational practices in hospital physicians providing ward coverage. A prospective, controlled intervention was conducted in two surgical and two internal wards. The intervention was based on physician quality circles - a participative technique to involve employees in the development of solutions to overcome work-related stressors. Outcome measures were the frequency of observed workflow interruptions. Workflow interruptions by fellow physicians and nursing staff were significantly lower after the intervention. However, a similar decrease was also observed in control units. Additional interviews to explore process-related factors suggested that there might have been spill-over effects in the sense that solutions were not strictly confined to the intervention group. Recommendations for further research on the effectiveness and consequences of such interventions for professional communication and patient safety are discussed.
\end{abstract}

Keywords: workflow interruptions, hospital physicians, intervention, control study, observation

\section{INTRODUCTION}

Workflow interruptions in healthcare professionals are considered to jeopardize clinical performance and, potentially, negatively affect the quality of patient care [1,2]. Firstly, in various professional groups, interruptions and distractions are prevalent in daily hospital practice [3-7]. Secondly, interruptive and distractive clinical work may result

*Corresponding author: Matthias Weigl, Dr. Institute and Outpatient Clinic for Occupational, Social, and Environmental Medicine, Ludwig-Maximilians-University Munich, Ziemssenstrasse 1, D-80336 Munich, Germany. Phone: ++49-89-5160-5311; Fax: -5306. Email: matthias.weigl@med.lmu.de. Other Authors: Severin.Hornung@inet.polyu.edu.hk; juergen.glaser@uibk.ac.at; peter.angerer@uni-duesseldorf.de. 
in higher mental workload, aggravated work stress, and suboptimal clinical performance [8-11]. Thirdly, workflow interruptions are regarded to be responsible for detrimental safety and quality practices in health care delivery [1, 2, 12-14]. Highly interruptive clinical environments may lead to suboptimal staff communication, unfocused diagnostic procedures, deficient handovers, and/or medication errors during drug administration $[5,14-16]$.

Workflow interruption is defined as a secondary activity that requires one's attention and stops interaction with the primary activity. For example, a beeper call interrupts a physician while talking to a patient, urges him/her to call back, and to postpone the communication with the patients for two minutes [17, 18].

\subsection{Interventions on Workflow Interruptions in Clinical Environments}

To limit the detrimental potential of interruptions as a safety hazard for healthcare professionals, custom-tailored, and effective interventions are necessary. The current evidence on interventions addressing workflow interruptions in clinical environments shows a number of limitations. Firstly, there exists a lack of evidence on interventions addressing enhanced inter-professional coordination and communications. The few reported interventions to reduce frequent workflow interruption in healthcare staff address different causal factors [2]; such interventions mostly include behavior modification, staff education, and use of "do-not interrupt signage"-vests [e.g., 16, 19, 20]. Also, use of technology, such as clinical information systems, and its potential impact on workflow interruptions have been evaluated [e.g., 21]. However, potential effects of improved inter-professional communication and coordination for workflow in hospital settings still need to be studied [6]. Secondly, to our knowledge, studies addressing interventions on workflow interruptions of hospital physicians are scarce. In the literature, we found only one study investigating an intervention to reduce interruptions in physician-patient encounters [22]. A limited number of other intervention studies have addressed this phenomenon, but have almost exclusively focused on nursing staff $[16,19,23]$. However, due to the unique nature of hospital physician work and the limited comparability with nursing work, specific investigations into the character and frequency of hospital physicians' workflow interruptions and routines are necessary [24]. Thirdly, interventions are mostly limited to certain clinical procedures and neglect an overall level of workflow interruptions over the course of extended work periods, although the study of overall workload of the physicians' entire shift is important. Although there is strong rationale to address clinical care procedures that are highly susceptible to impaired safety, such as medication administration $[16,19,20]$ or physician-patient encounters [22], prolonged work periods are widely understudied. It is difficult to capture and measure overall workflow outcomes in clinical environments [24]; however, extended observation periods enable a valid and robust investigation of work routines and the general level of workflow interruptions that hospital physicians face [17]. Furthermore, in intervention studies, there is a lack of controlled designs and research studies illustrating the long-term effectiveness of interventions. Additionally, just a few published studies apply pre- and post-assessments [e.g., 19, 23]. However, the effectiveness of interventions based on comparisons with similar control groups, as 
well as their sustainability over extended time periods, e.g., one year, have not yet been studied. Finally, studies in real hospital environments enable a robust investigation of the effectiveness of intervention approaches in healthcare settings and extend external validity of the findings.

Interventions to reduce interruptions should be sensitive to the complexity of healthcare, the special requirements of intra- and inter-professional communication, as well as to the nature and purpose of disruptive incidents in clinical care [2]. Therefore, participation of the affected physicians in the process of re-designing work and care processes to contain or reduce interruptions is essential. Participative approaches in improvement of work conditions are particularly well established in the area of participative ergonomics $[25,26]$. Active involvement of employees in the re-design or restructuring of detrimental ergonomic factors at work has shown to benefit various outcomes, i.e., less musculoskeletal symptoms, injuries, compensation claims, and reduced sick leaves [26]. Moreover, we hypothesized that unit-based interventions to reduce workflow interruptions are effective if they adhere to the following requirements: (a) be conducted as a structured and participatory process; (b) identify inappropriate or stress-inducing workflow interruptions; and (c) develop specific solutions to contain and reduce workflow interruptions in hospital physicians' work.

\subsection{Study Objectives}

The aims of the current study were to address some of the above mentioned limitations. Specifically, drawing on an intervention-control design in a hospital in Germany, we sought to estimate the effectiveness of a unit-based re-organization of hospital physicians' daily work practices to reduce workflow interruptions.

\section{METHODS}

\subsection{Study Setting}

The study was conducted in a 300-bed general community hospital in southern Germany (11 departments; about 17,000 inpatients yearly; 100 physicians employed). This intervention study was part of an initiative to improve hospital physicians' working conditions and the quality of patient care supported by The German Medical Association. This pilot project aimed to improve hospital physicians' work life and well-being through participatory work-design over the course of one year [27]. The study was approved by the Ethics Committee of the Faculty of Medicine of the first author's university.

\subsection{Intervention-Control Design, Intervention, and Observation Procedure}

Seven inpatient wards were included, that were well comparable in terms of work organization, bed capacity, and staffing levels: four for internal medicine (two gastroenterology wards and two cardiology wards) and three for surgical inpatients (one general and two trauma surgery wards). To achieve a prospective, controlled intervention design, a baseline assessment prior to the intervention was carried out in all seven wards. The duration of the baseline assessment was three months. Afterwards, a cluster randomization was conducted such that an intervention and a control unit were 
picked for surgery and internal medicine, respectively. Eventually, four wards were randomly selected as intervention units, i.e., two cardiology and two trauma surgery wards, and three wards formed the control group, i.e., the general surgery and gastroenterology wards. The overall duration of the intervention itself was ten months. After the intervention, all units were included in the post-intervention assessment which took place one month after the end of the intervention. The final data collection lasted about three months. To avoid differences in seasonal patterns as confounding factors, the baseline and the final data collection covered almost the same time of the year.

The intervention was based on continuous small group meetings, i.e., 'quality circles'. Quality circles are a participative technique to involve employees in the development and implementation of solutions to overcome work-related obstacles and stressors, and have proven to be effective for productivity, job performance, and job satisfaction $[28,29]$. The involved physicians of the intervention units aimed to reduce frequent workflow interruptions in their daily work in the inpatient wards. Physicians in the control units did not form quality circles; however, they were also offered feedback on the baseline assessment and had access to information on the contents and progress of the intervention on the hospital's intranet.

Workflow interruptions and distractions in hospital physicians' daily work practice were assessed through structured full-shift observations. Expert observations using standardized methods have shown to be valid and reliable for healthcare services $[30,31]$. Standardized observations are particularly useful for the detailed investigation of workflow interruptions and distractions in healthcare practice $[2,7,11,17,32]$. Full shift observations serve as meaningful way to cover extended time periods and enhance the validity of the observational results in dynamic clinical work environments [33-35]. Four observers conducted the observations. Two had prior experience in participant observations in clinical environments; the other two were also familiar with hospital physicians' work due to their professional background. All were trained prior to the assessments, familiarized with the study site, and tested for inter-rater agreement (see section 2.4). All observers followed the physicians throughout the entire shift and coded workflow interruptions [17]. The start and end of a work shift were recorded based on the observed physician's self-report, e.g., the physician declares that he/she now starts his/her work shift, or leaves for home. Observers were instructed not to distract or interrupt physicians or co-workers (e.g., not to start a conversation). All observations took place before the intervention meetings (baseline) as well as after the intervention meetings and implementation phase (post-intervention assessment).

Additionally, we aimed to obtain information on factors concerning the progress and implementation of the solutions, i.e., aspects that supported or hindered the process of the implementation. Semi-structured interviews with involved physicians were conducted during the post-intervention assessment; results are reported in section 3.2.

\subsection{Study Sample}

Most participants were resident physicians undergoing post-graduate specialty training. Only those assigned to inpatient ward coverage throughout the entire shift on one of the seven pre-specified wards were observed. Furthermore, we only included physicians 
working in the hospital for at least four months to ensure an adequate level of proficiency. Observation dates were selected randomly. Physicians' participation was voluntary, and their consent was obtained prior to scheduling the observations.

For the baseline assessment phase, 20 full-shift observations were conducted: 11 in the intervention wards and 9 in the control wards. Overall, 17 physicians participated in the observations (10 Internal Medicine, 7 Surgery) and three physicians were observed twice. For the post-assessment, 31 full-shift observations were conducted: 15 in the intervention and 16 in the control units. Overall, 21 ward physicians participated, 10 of whom were observed twice.

To detect and categorize workflow interruptions, an established tool was implemented [17]. It defined workflow interruption in hospital physicians' work as an unplanned and unscheduled interference by another person, causing a discontinuation of the present tasks, a noticeable break, or a necessary switch from one task to another. The tool distinguished among 3 categories or sources of workflow interruptions [17]: (a) interruptions by fellow physicians (e.g., another physician asks for support while the observed physician is filling out patients' charts); (b) by nursing staff (e.g., a nurse enters a physician's office and asks for a document while the physician is talking on the phone); and (c) by others (e.g., patients, relatives of patients, non-clinical employees, and unspecified other persons). Additionally, a sum score was computed, indicating the overall amount of workflow interruptions.

\subsection{Observation Tool: Pilot Testing of Reliability}

Prior to both time points, pilot observations were conducted to test the reliability of the observation tool and the proficiency of the respective raters. To check for interrater reliability, the two observers followed the same hospital physicians and simultaneously rated workflow interruptions. At baseline, six ward physicians were observed simultaneously (range of observation periods: 34.5 - $69 \mathrm{~min}, 291.5 \mathrm{~min}$ in total). A total of 101 workflow interruptions were coded (Rater 1: $\mathrm{N}=47$; Rater 2: $\mathrm{N}=54)$. The resulting Kappa-coefficient was $0.65(\mathrm{~T}=23.9 ; \mathrm{p}=0.00)$. Before the post-intervention assessment, the two raters simultaneously observed three physicians (Range 56-75 $\mathrm{min}, 190.0 \mathrm{~min}$ in total). A total of 31 workflow interruptions were identified (Rater $1: \mathrm{N}=17$; Rater 2: $\mathrm{N}=15$ ). The resulting Kappa-coefficient of $0.68(\mathrm{~T}=9.45 ; \mathrm{p}<0.01)$ indicates sufficient inter-rater agreement and measurement reliability in both pilot observations [36].

\subsection{Analysis}

At both time-points, data were recorded on clipboard paper sheets, transferred via double-data entry into a data base, and checked for implausible values. For descriptive statistics, we first computed means and sum values for the three categorized interruption sources under study. We used adjusted frequency values accounting for different observation periods by computing the average number of observed workflow interruptions per hour. T-tests were used to assess inter-group differences in interruption frequencies between the intervention and the control groups as well as intra-group differences between measurement points. Cohen's d was computed to indicate effect 
sizes for the mean change over time. According to Cohen [37], effect sizes can be classified into small $(0.2<\mathrm{d}<0.4)$, medium $(0.5<\mathrm{d}<0.7)$, and large $(\mathrm{d}>0.8)$. All analyses were performed using PASW Statistics 19.0. Regarding the number of observations before and after the intervention, a power calculation was not conducted.

\section{RESULTS}

\subsection{Process and Contents of the Intervention on Workflow Interruptions}

Volunteering physicians in the intervention wards met after work, discussed, analyzed and collectively prioritized problematic work conditions, developed adequate selfdesigned solutions, and supervised their implementation [28]. Although participants themselves were responsible for the implementation of the developed solutions, the hospital's management supported the intervention and explicitly permitted physicians to experiment with alternative ways of organizing their work activities. Physicians in the intervention units had three 1.5-hour meetings to develop solutions for containing and/or reducing inappropriate workflow interruptions and distractions, as described below:

(1) In the first meeting, physicians discussed situations with high frequency of inappropriate interruptions and were additionally informed about the data collected during the baseline assessment. They identified and categorized these situations, analyzed the potential underlying causes, and suggested measures to address them. Table 1 summarizes the identified situations, the norms prior to the intervention, and the developed solutions. Finally, the physicians decided to invite the head nurses of the respective wards to the next meeting because many solutions involved nursing work and the established care routines.

(2) The second meeting aimed to discuss the implications of the suggested changes in work routines for the collaboration between physicians and nurses. The head nurse of the respective ward contributed the nursing staff's perspective on the suggested solutions. Nurses' suggestions for necessary adjustments and/or implementation issues were included in the project agenda.

(3) In the third and final meeting, physicians discussed the implementation status of the suggested solutions, achieved improvements, potential problems hindering timely implementation, ways to overcome these obstacles, as well as adjustments to the solutions and/or the timeline of their implementation.

\subsection{Implementation Status and Process-Oriented Aspects of the Intervention}

After the intervention, two involved physicians were interviewed. The clinicians reported that the initiative reduced workflow interruptions through restructuring nursephysician communication, and streamlining care processes was perceived positively by clinicians and nurses in the unit. In the cardiology wards, the proposed solutions were regarded as completely implemented in daily practice, whereas in the trauma surgery wards, the solutions were considered as to be in progress. With regards to critical factors for implementation and sustainability of the proposed solutions, both clinicians mentioned the importance of close cooperation with the head nurse of the units. They 


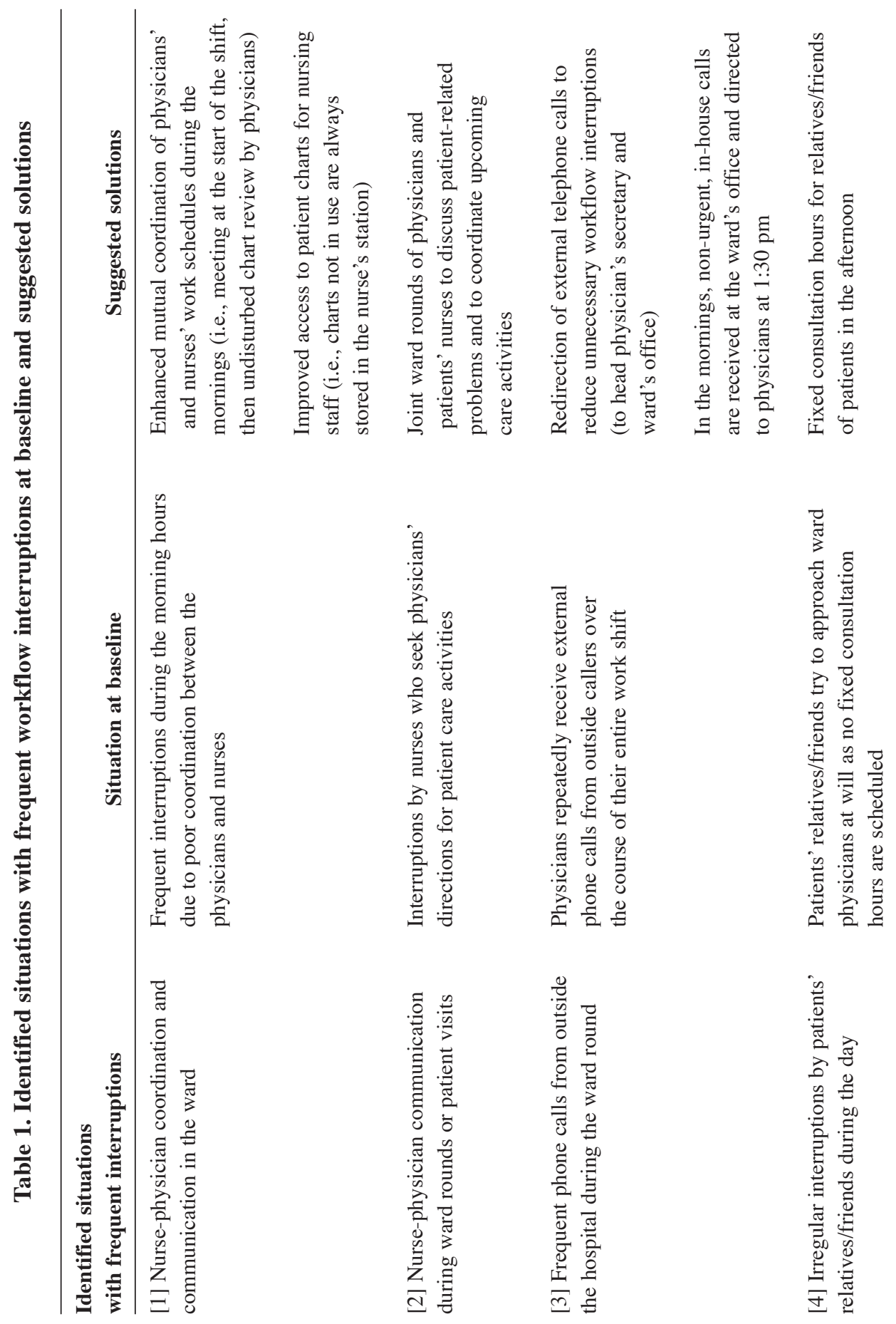


experienced an improved coordination with the nursing staff during the ward rounds, and less interruptions during the chart review and office work. Challenges were the continuous progress updates for non-involved physicians about the proposed solutions as well as the sustained support from head physicians. Finally, the physicians reported that several solutions could not be strictly confined to the intervention unit. Due to joint physician meetings of the internal and surgical departments, physicians in the control departments received information about the intervention and started to implement several solutions on their own, e.g., restricted consultation hours for patients' relatives.

\subsection{Effects on Observed Frequency of Workflow Interruptions}

Overall, 51 full-shift observations of hospital physicians providing ward coverage were conducted. Table 2 presents information on observation periods, i.e., physicians' full work shifts. Observed shifts were evenly assigned over group (control/intervention) and time (pre/post-assessment), with $\mathrm{Chi}^{2}(\mathrm{df}=1)=2.13$, not significant. The overall duration of the observation was 464.9 hours. The average shift duration was 9 hours, 4 minutes, and 18 seconds, standard deviation (SD, hh:mm:ss) 00:43:31, range 07:26:33 - 10:28:06. In testing if the average shift duration changed over time, within the control units, we notified significantly longer shifts at the post-intervention assessment, with $\mathrm{t}(\mathrm{df}=24)=-4.66, \mathrm{p}<$ .01 . The same trend was also observed for the intervention units: $\mathrm{t}(\mathrm{df}=23)=-2.63, \mathrm{p}=.02$.

The purpose of the study was to test if the intervention reduced workflow interruptions substantially in the intervention departments. Table 3 presents the adjusted frequency of three sources, as well as the overall frequency of workflow interruptions (number of interruptions per hour) over the two study groups, pre- and post-intervention assessment.

First, we conducted mean difference tests to check for significant differences between the intervention and control units at baseline. Observed average level of workflow interruptions was statistically equivalent for interruptions by fellow physicians $(\mathrm{t}(\mathrm{df}=181)=.25, \mathrm{p}=.80)$ as well as by nurses $(\mathrm{t}(\mathrm{df}=181)=-.27, \mathrm{p}=.79)$. Only interruptions by others were significantly more frequent in control units $(\mathrm{t}(\mathrm{df}=$ $181)=-3.23, \mathrm{p}<.00)$. The overall score of disruption events was also similar between the units $(\mathrm{t}(\mathrm{df}=181)=-1.7, \mathrm{p}=.09)$.

Table 3 presents differences in the three interruption categories over time and across groups. Workflow interruptions by fellow physicians were reduced in the intervention units (IU) to a greater extent than in the control units (CU) (IU: $\Delta \mathrm{M}=-.49, \mathrm{t}(\mathrm{df}=250)=$ $.49, \mathrm{p}<.01 ; \mathrm{CU}: \Delta \mathrm{M}=-.29, \mathrm{t}(\mathrm{df}=243)=2.0, \mathrm{p}=.05)$. With regard to the magnitude of change, the effect size for the IU is somewhat greater $(\mathrm{d}=.41)$ than in the CU $(\mathrm{d}=.26)$. For interruptions by nurses, we observed a significantly reduced interruptions in the postintervention assessment for the IU $(\Delta \mathrm{M}=-.39, \mathrm{t}(\mathrm{df}=250)=2.12, \mathrm{p}=.04)$. However, for the $\mathrm{CU}$, this change was even greater $(\Delta \mathrm{M}=-.52, \mathrm{t}(\mathrm{df}=243)=3.19, \mathrm{p}<.01)$. The average level of interruptions by others did not change in the IU during the study. However, in the $\mathrm{CU}$, we observed a significant decrease in workflow interruptions by others $(\Delta \mathrm{M}=-.47$, $\mathrm{t}(\mathrm{df}=243)=2.10, \mathrm{p}=.04)$. In terms of effect sizes, both differences can be classified as small (IU: $\mathrm{d}=.13$; CU: $\mathrm{d}=.28$ ). The overall frequency of observed interruptive events in both groups showed a highly significant decrease over time (IU: $\Delta \mathrm{M}=-1.05, \mathrm{t}(\mathrm{df}=250$ ) 
Table 2. Characteristics of observation sample

\begin{tabular}{lcccc}
\hline & \multicolumn{2}{c}{ Intervention units } & \multicolumn{2}{c}{ Control units } \\
\hline & Baseline & $\begin{array}{c}\text { Post- } \\
\text { intervention }\end{array}$ & Baseline & $\begin{array}{c}\text { Post- } \\
\text { intervention }\end{array}$ \\
\hline Observed Shifts & 11 & 15 & 9 & 16 \\
Overall observation time (hh:mm:ss) & $91: 54: 00$ & $141: 13: 23$ & $78: 51: 16$ & $150: 40: 54$ \\
Shift duration (Mean, hh:mm:ss) & $08: 21: 16$ & $09: 24: 53$ & $08: 45: 41$ & $09: 25: 03$ \\
Shift duration (Standard deviation, & & & & \\
hh:mm:ss) & $00: 35: 39$ & $00: 38: 41$ & $00: 21: 12$ & $00: 45: 32$ \\
\hline
\end{tabular}

Table 3. Observed workflow interruptions per hour over study time and group

\begin{tabular}{|c|c|c|c|c|c|c|c|c|c|c|c|c|}
\hline & \multicolumn{6}{|c|}{ Intervention units } & \multicolumn{6}{|c|}{ Control units } \\
\hline & Base & line & $\begin{array}{r}\text { Po } \\
\text { interve }\end{array}$ & $\begin{array}{l}\text { st- } \\
\text { ention }\end{array}$ & $\begin{array}{r}\text { Test } \\
\text { and efi } \\
\text { size fo } \\
\text { mea } \\
\text { chan }\end{array}$ & $\begin{array}{l}\text { ect } \\
\text { or } \\
\text { ge }\end{array}$ & Base & line & $\begin{array}{r}\text { Po } \\
\text { interv }\end{array}$ & $\begin{array}{l}\text { st- } \\
\text { ention }\end{array}$ & $\begin{array}{c}\text { Test } \\
\text { and effec } \\
\text { size for } \\
\text { mean } \\
\text { change }\end{array}$ & $\begin{array}{l}\text { ect } \\
\text { o }\end{array}$ \\
\hline & $(\mathrm{N}=$ & : 98) & $(\mathrm{N}=$ & 154) & $(\mathrm{df}=2$ & 50) & $(\mathrm{N}=$ & $85)$ & $(\mathrm{N}=$ & 160) & $(\mathrm{df}=243$ & +3) \\
\hline & M & $\mathrm{SD}$ & $\mathrm{M}$ & $\mathrm{SD}$ & $\Delta \mathrm{M}$ & $\mathrm{d}$ & $\mathrm{M}$ & $\mathrm{SD}$ & $\mathrm{M}$ & $\mathrm{SD}$ & $\Delta \mathrm{M} \quad \mathrm{c}$ & $\mathrm{d}$ \\
\hline $\begin{array}{l}\text { Interruptions by } \\
\text { fellow physicians }\end{array}$ & .98 & 1.49 & .49 & .83 & $-.49 * *$ & .41 & .93 & 1.18 & .64 & 1.01 & $-.29 * \quad .2$ & .26 \\
\hline $\begin{array}{l}\text { Interruptions by } \\
\text { nursing staff } \\
\text { Interruptions by }\end{array}$ & 1.38 & 1.48 & .99 & 1.38 & $-.39 *$ & .27 & 1.44 & 1.46 & .92 & 1.05 & $-.52 * * .4$ & .41 \\
\hline $\begin{array}{l}\text { others } \\
\text { Overall } \\
\text { interruptions }\end{array}$ & 1.34 & 1.43 & 1.16 & 1.23 & -.17 & .13 & 2.12 & 1.83 & 1.64 & 1.59 & $-.47 * \quad .2$ & .28 \\
\hline
\end{tabular}

Note: Data are frequency of interruption or number of interruptions per hour, in $1 / \mathrm{hr} ; \mathrm{N}=$ Number of observed shifts; $\mathrm{M}=$ Mean of observed workflow interruptions per hour; $\mathrm{SD}=$ Standard deviation; $* * \mathrm{p}<.01,{ }^{*} \mathrm{p}<.05$.

$=3.10, \mathrm{p}<.01 ; \mathrm{CU}: \Delta \mathrm{M}=-1.27, \mathrm{t}(\mathrm{df}=243)=3.61, \mathrm{p}<.01)$. Both effect sizes (IU: $\mathrm{d}=$ .39; $\mathrm{CU}: \mathrm{d}=.46$ ) indicate small to medium changes [37].

Finally, we also tested for mean differences between IU and CU in the postintervention assessment, and found no significant differences for interruptions due to fellow physicians $(\mathrm{t}(\mathrm{df}=312)=-1.44 ; \mathrm{p}=.15)$ or nurses $(\mathrm{t}(\mathrm{df}=312)=.50 ; \mathrm{p}=.62)$. In the third category, in the $\mathrm{CU}$, the average level of observed interruption by others was higher than that in the $\mathrm{IU}(\mathrm{t}(\mathrm{df}=312)=-2.99 ; \mathrm{p}<.01)$. Also, for the overall frequency of interruptive events, there is a significant difference between the groups under study. In the $\mathrm{CU}$, the overall frequency of interruptions by persons was higher than that in the $\mathrm{IU}(\mathrm{t}(\mathrm{df}=312)=-2.17, \mathrm{p}=.03)$. 


\section{DISCUSSION}

\subsection{Discussion of Current Results}

This study aimed to investigate the effectiveness of an intervention on reducing workflow interruptions of ward physicians by applying a prospective interventioncontrol design. The frequency of workflow interruptions was recorded through fullshift expert observations. The results demonstrate that physicians face multilayered interruptions during their clinical work and that interruptions are frequently caused by a variety of clinical coworkers [11, 17]. Specifically, interruptions by nurses and other clinical personnel occurred most often. This reflects the high degree of intra- and interprofessional communication in hospital work and its inherent risk for disruptive clinical work [1, 2, 24, 38]. Although in our sample, the overall frequency of interruptions is lower compared to acute clinical environments, the distribution across the different sources of interruptions is in line with previous studies in hospital wards $[2,3,18,33,38]$.

The intervention enabled hospital physicians to identify inappropriate workflow interruptions, discuss potential causes and implications, and develop adequate solutions to mitigate the level of workflow interruptions during ward coverage. Thus, our intervention contributed to approaches in participatory ergonomics as, to our knowledge, our participatory intervention for the first time specifically addressed workflow interruptions [26]. The self-developed solutions mainly featured smoothening of clinicians' work processes such as the intra- and inter-professional communication and coordination [25]. In collaboration with the nursing staff, the physicians aimed at streamlining work organization in the ward and to improve mutual coordination with nursing staff. The involved physicians aimed at establishing interruption-free periods for managing clinical work and mastering charting and documentation tasks in the back office. Furthermore, the physicians intended to improve the physicians-nurse coordination and collaboration by conducting joint ward rounds, which enable the discussion of patient-related matters immediately. The proposed solutions demonstrate a way to address and diminish "interruptive communication mechanisms" between healthcare professionals [6, 24]. Moreover, the variety of solutions proves that multifactor approaches are needed to reduce workflow interruptions in health care environments [19].

Overall, we found limited evidence that the intervention was effective. The overall frequency of workflow interruptions in the intervention units decreased significantly over time; specifically, on average, one interruption event fewer was recorded per observation hour after the intervention (see Table 3). Particularly, interruptions by fellow physicians and nursing staff post-intervention were decreased compared to baseline. Our observational time lag shows that changes were observable after one year from the start of the project. However, almost a similar trend was also observed in the control units; i.e., the observed frequency of workflow interruptions decreased significantly over time (Table 3 ).

The significant decrease in the workflow interruptions in the control units can be due to the following three reasons: (i) Spill-over effects: In conducting intervention-control studies in real hospital settings, it is difficult to prevent contamination, because ideas 
and experiences are easily brought from the intervention to the control group [39]. In the present study, physicians of the intervention and control departments held joint case conferences on a daily basis, monthly inter-departmental meetings, and joint on-call services. As reported in the interviews, some solutions were not strictly restricted to the intervention units and were eventually transferred and implemented in the control units, through informal communication of the physicians and nurses between the two groups. Due to the high workload, physicians are always interested in adopting measures to optimize workflow and, thus, effective and successful solutions may have been copied instantly within the control units, an example of observational learning or mastery modeling of successful implementation. (ii) Hospital-wide quality improvement initiative: Hospitals routinely undertake various efforts to improve quality and efficiency of care practices on different levels. During the current study, the hospital conducted quality improvement initiatives, e.g., quality management. Hence, spurious effects of our intervention and of the hospital quality improvement activities may have occurred, particularly, as a number of physicians who participated in our study were intermittently involved in hospital-wide quality improvement activities. (iii) Observer effects: Standardized observations are particularly feasible for the detailed investigation of work flow interruptions and distractions in healthcare practices [2, 15, 17]. However, observations in applied healthcare settings bear the potential of unintended observer effects that may bias the prevalence of interruptions' frequencies; for example, colleagues did not interrupt as they knew about the intervention, or observed physicians avoided certain clinical procedures prone to interruptions. Although our observations are reliable and based on sufficient inter-rater agreement, we could not exclude that observed physicians and their colleagues in the control units acted unintentionally in a way to reduce interruptions recorded during the post-intervention assessment.

Overall, to our knowledge, this is the first study investigating the effect of an intervention to reduce workflow interruption in hospital physicians by applying a controlled-intervention design. Considering the difficulties to find appropriate control groups in a real hospital and to conduct intervention studies over an extended period, the study presents a feasible intervention to reduce mistimed workflow interruptions in physicians providing ward coverage.

\subsection{Limitations of the Study}

This study's results should be perceived in light of several limitations. First, the study is limited to physicians providing ward coverage. Therefore, the prevalence of disruptive events is different from emergency and immediate care environments, which are prone to even more frequent interruptions [12, 33, 40]. In Germany, mostly junior physicians undergoing specialty training are responsible for ward coverage. Senior physicians face different clinical work load and, due to their supervisory obligations, they may also be prone to additional interruptions caused by, for example, their subordinate junior physicians [41]. The results are based on one German Hospital. Although we checked for comparability in terms of size, patient load, and structure, selection bias may have occurred as the study hospital may be different than others in making efforts to enhance quality. We used cluster randomization as a way to assign the 
hospitals units to either intervention or control group, but an ideal study design to infer causality may be a randomized controlled intervention trial. Although we included comparable units in the study, we could not exclude that certain work practices are different between the intervention and the control units. In regard to the progress status of the implementation in the intervention units, we did not check for potential differences in the overall effectiveness of the intervention between 'early' implementer and 'late' implementer units. Future studies should take this into account as effects may be related to the progress status of the implementation.

A major limitation exists for the study's definition of observed workflow interruptions in regards to the nature and appropriateness of workflow interruptions for clinical procedures. We recorded clearly observable, pre-defined workflow interruptions. However, interruptions in clinical work have different effects and safety implications [2, 42-44]. Interruptions can be purposeful, ensuring a quick and successful function of healthcare delivery or providing timely critical information $[2,44]$. As our observational approach did not quantify whether interruptions were medically related, we could not infer if the interruptions occurred for a positive reason. This refers to the content of workflow interruptions, where interruptive colleagues may actually provide valuable clinical or process-related information such as acute error capture or necessary information during emergency care $[2,33]$. This also refers to appropriate situations (or "opportune moments"). Colleagues might pick appropriate times to interrupt each other whereas 'random' interruptions occur accidently or arbitrarily, such as beeper calls $[17,43]$. We did not take into account physicians' individual appraisal of interruptive events, which might differ substantially in terms of purpose, severity, temporal duration, or nature of the event $[45,46]$. For instance, in particular situations, senior physicians may encourage junior colleagues to interrupt as a means to foster communication or effective learning. Finally, we mainly covered human-to-human interruptions as these comprise the major share of workflow interruptions in ward physicians $[17,38]$. However, in our observation approach, we were not able to entirely identify all potential human-technology interruptions. Through the increasing adoption of technology in health care, future studies should address the impact of technology-related workflow interruptions and their potential impact on smoothness of workflow, task completion, and patient safety.

\subsection{Study Implications and Future Research}

This study's results carry several implications. Clinically, our study shows that reducing mutual workflow interruptions by structuring inter-professional collaboration can be a promising strategy. To engage physicians in addressing and reducing unnecessary workflow interruptions is a feasible option to improve physicians' quality at work in the hospital. The results corroborate that improvement and thorough appraisal of nursephysician communication and coordination reduces mistimed workflow interruptions by colleagues and nursing staff. This is in line with the call for enhanced interprofessional collaboration through better organization of various tasks and deliberate design of joint activities, communication processes, and information transfer [47, 48]. However, the potential impact of this initiative for enhanced performance, patient outcomes, as well as clinical safety needs to be addressed [48]. 
Regarding implications for future research, this study provides ground for further issues to address. One question remains in regard to the role of interruptions in healthcare delivery and relative strategies to design interruption resilient work practices' for hospital physicians [2]. Future studies should examine and evaluate strategies to reduce workflow interruptions in a two-folded perspective: On the one hand, identify and maintain inevitable, necessary interruptions that ensure clinical collaboration and safety; on the other hand, reduce or contain inappropriate, unnecessary interruptions that are counterproductive to patients' and staff's outcomes [2]. Future engineering approaches should also take into account to what extent certain tasks and clinical work practices increase the risk for inappropriate workflow interruptions, and to what extent interruptions help to streamline patient care in certain circumstances. Furthermore, research investigating effectiveness of interruption interventions should incorporate various outcome measures, such as observational, selfreport, clinical, and qualitative data. As we found no superior effect of the intervention in comparison to the control group, we also encourage future studies to investigate potential confounding factors for the effectiveness of the intervention, possibly including seasonal patterns (of types of patients or volume of patient census) and accumulation of physicians' and nursing staff's knowledge over time. Moreover, to investigate potential negative effects for various stakeholders in a hospital setting, the perspectives of non-involved professional groups in the evaluation process should be integrated, as potential solutions in favor of the physicians may bring forth disadvantages to other professions involved in patient care.

\section{CONCLUSIONS}

The present study found that a participatory intervention targeting hospital physicians decreased observed workflow interruptions significantly after 13 months. However, the effects cannot be attributed exclusively to the intervention. Specifically, the same pattern of reduced workflow interruptions was also found in the control units. The study corroborates that to reduce workflow interruptions, health care environments need to become better designed socio-technical systems, balancing intra-professional and interprofessionals interactions and coordination in healthcare delivery.

\section{ACKNOWLEDGEMENTS AND FUNDING}

We thank Andrea Zupanc, Anne Bradac, and Beate Huber for their support in data collection. The study was funded by the German Medical Association (Grant No. 06-73) and Munich Center of Health Sciences.

\section{CONFLICT OF INTEREST}

The authors indicated no potential conflicts of interest.

\section{REFERENCES}

[1] Grundgeiger T, Sanderson P. Interruptions in healthcare: theoretical views. Int J Med Inform. 2009, 78(5):293-307.

[2] Rivera-Rodriguez AJ, Karsh BT. Interruptions and distractions in healthcare: review and reappraisal. Qual Saf Health Care. 2010, 19(4):304-12. 
[3] Chisholm CD, Dornfeld AM, Nelson DR, Cordell WH. Work interrupted: a comparison of workplace interruptions in emergency departments and primary care offices. Ann Emerg Med. 2001, 38(2):146-51.

[4] Dearden A, Smithers M, Thapar A. Interruptions during general practice consultations - the patients' view. Fam Pract. 1996, 13(2):166-9.

[5] O'Shea E. Factors contributing to medication errors: a literature review. J Clin Nurs. 1999, 8(5): 496-504.

[6] Coiera E, Tombs V. Communication behaviours in a hospital setting: an observational study. Bmj. 1998, 316(7132):673-6.

[7] Kalisch BJ, Aebersold M. Interruptions and multitasking in nursing care. Jt Comm J Qual Patient Saf. 2010, 36(3):126-32.

[8] Jett QR, George JM. Work interrupted: A closer look at the role of interruptions in organizational life. Acad Manage Rev. 2003, 28(3):494-507.

[9] Hakimzada AF, Green RA, Sayan OR, Zhang J, Patel VL. The nature and occurrence of registration errors in the emergency department. Int J Med Inform. 2008, 77(3):169-75.

[10] Wiegmann DA, ElBardissi AW, Dearani JA, Daly RC, Sundt TMI. Disruptions in surgical flow and their relationship to surgical errors: an exploratory investigation. Surgery. 2007, 142(5):658-65.

[11] Westbrook JI, Coiera E, Dunsmuir WT, Brown BM, Kelk N, Paoloni R, et al. The impact of interruptions on clinical task completion. Qual Saf Health Care. 2010, 19(4):284-9.

[12] Brixey JJ, Tang Z, Robinson DJ, Johnson CW, Johnson TR, Turley JP, et al. Interruptions in a level one trauma center: a case study. Int J Med Inform. 2008, 77(4):235-41.

[13] Sevdalis N, Sonal A, Undre S, Vincent CA. Distractions and Interruptions in the Operating Room. In: Flin R, Mitchell L, Editors. Safer Surgery. Farnham: Ashgate, 2009. 405-19.

[14] Flynn EA, Barker KN, Gibson JT, Pearson RE, Berger BA, Smith LA. Impact of interruptions and distractions on dispensing errors in an ambulatory care pharmacy. Am J Health Syst Pharm. 1999, 56(13):1319-25.

[15] Westbrook JI, Woods A, Rob MI, Dunsmuir WT, Day RO. Association of interruptions with an increased risk and severity of medication administration errors. Arch Intern Med. 2010, 170(8):683-90.

[16] Biron AD, Loiselle CG, Lavoie-Tremblay M. Work interruptions and their contribution to medication administration errors: an evidence review. Worldviews Evid Based Nurs. 2009, 6(2):70-86.

[17] Weigl M, Muller A, Zupanc A, Glaser J, Angerer P. Hospital doctors' workflow interruptions and activities: an observation study. BMJ Qual Saf. 2011, 20(6):491-7.

[18] Li SY, Magrabi F, Coiera E. A systematic review of the psychological literature on interruption and its patient safety implications. J Am Med Inform Assoc. 2012 , 19(1):6-12.

[19] Relihan E, O'Brien V, O'Hara S, Silke B. The impact of a set of interventions to reduce interruptions and distractions to nurses during medication administration. Qual Saf Health Care. 2010, 19(5):1-6.

[20] Pape TM. Applying airline safety practices to medication administration. Medsurg Nurs. 2003, 12(2):77-93.

[21] Ballermann MA, Shaw NT, Arbeau KJ, Mayes DC, Noel Gibney RT. Impact of a critical care clinical information system on interruption rates during intensive care nurse and physician documentation tasks. Stud Health Technol Inform. 2010, 160(Pt 1):274-8.

[22] Peleg R, Froimovici M, Peleg A, Milrad V, Ohana G, Fitoussi S, et al. Interruptions to the physicianpatient encounter: an intervention program. Isr Med Assoc J. 2000, 2(7):520-2.

[23] Pape TM, Guerra DM, Muzquiz M, Bryant JB, Ingram M, Schranner B, et al. Innovative approaches to reducing nurses' distractions during medication administration. J Contin Educ Nurs. 2005, 36(3):108-16.

[24] Laxmisan A, Hakimzada F, Sayan OR, Green RA, Zhang J, Patel VL. The multitasking clinician: decision-making and cognitive demand during and after team handoffs in emergency care. Int J Med Inform. 2007, 76(11-12):801-11. 
[25] van Eerd D, Cole D, Irvin E, Mahood Q, Keown K, Theberge N, et al. Process and implementation of participatory ergonomic interventions: a systematic review. Ergonomics. 2010, 53(10):1153-66.

[26] Rivilis I, Van Eerd D, Cullen K, Cole DC, Irvin E, Tyson J, et al. Effectiveness of participatory ergonomic interventions on health outcomes: A systematic review. Applied Ergonomics. 2008, 39(3):342-58.

[27] Weigl M, Glaser J, Hornung S, Angerer P. Gestaltung ärztlicher Arbeit im Krankenhaus: Intervention und Evaluation (Design of medical work in the hospital: Intervention and Evaluation. In: Schwartz FW, Angerer P, editors. Arbeitsbedingungen und Befinden von Ärztinnen und Ärzten (Work conditions and Well-being of Physicians). Cologne: DAEV, 2009: 359-71.

[28] Pereira GM, Osburn HG. Effects of participation in decision making on performance and employee attitudes: A quality circles meta-analysis. J Bus Psychol. 2007, 22(2):145-53.

[29] Aust B, Ducki A. Comprehensive health promotion interventions at the workplace: experiences with health circles in Germany. J Occup Health Psychol. 2004, 9(3):258-70.

[30] Finkler SA, Knickman JR, Hendrickson G, Lipkin M, Jr., Thompson WG. A comparison of worksampling and time-and-motion techniques for studies in health services research. Health Serv Res. 1993, 28(5):577-97.

[31] Carthey J. The role of structured observational research in health care. Qual Saf Health Care. 2003, 12(2):ii13-6.

[32] Thomas EJ, Sexton JB, Helmreich RL. Translating teamwork behaviours from aviation to healthcare: development of behavioural markers for neonatal resuscitation. Qual Saf Health Care. 2004, 13(1):i57-64.

[33] Chisholm CD, Collison EK, Nelson DR, Cordell WH. Emergency department workplace interruptions: are emergency physicians "interrupt-driven" and "multitasking"? Acad Emerg Med. 2000, 7(11):1239-43.

[34] Gilchrist V, McCord G, Schrop SL, King BD, McCormick KF, Oprandi AM, et al. Physician activities during time out of the examination room. Ann Fam Med. 2005, 3(6):494-9.

[35] Weigl M, Muller A, Zupanc A, Angerer P. Participant observation of time allocation, direct patient contact, and simultaneous activities in hospital physicians. BMC Health Serv Res. 2009, 9(1):110.

[36] Landis JR, Koch GG. Measurement of Observer Agreement for Categorical Data. Biometrics. 1977, 33(1):159-74.

[37] Cohen J. Statistical power analysis for the behavioral sciences: L. Erlbaum Associates, 1988.

[38] Westbrook JI, Ampt A, Kearney L, Rob MI. All in a day's work: an observational study to quantify how and with whom doctors on hospital wards spend their time. Med J Aust. 2008, 188(9):506-9.

[39] Grant AM, Wall TD. The Neglected Science and Art of Quasi-Experimentation Why-to, When-to, and How-to Advice for Organizational Researchers. Organ Res Methods. 2009, 12(4):653-86.

[40] France DJ, Levin S, Hemphill R, Chen K, Rickard D, Makowski R, et al. Emergency physicians' behaviors and workload in the presence of an electronic whiteboard. Int J Med Inform. 2005, 74(10):827-37.

[41] Weigl M, Müller A, Vincent C, Angerer P, Sevdalis N. The association of workflow interruptions and hospital doctors' workload: a prospective observational study. BMJ Quality \& Safety. 2012, 2012, 21(5):399-407.

[42] Kreckler S, Catchpole K, Bottomley M, Handa A, McCulloch P. Interruptions during drug rounds: an observational study. Br J Nurs. 2008, 17(21):1326-30.

[43] Brixey JJ, Robinson DJ, Turley JP, Zhang J. The roles of MDs and RNs as initiators and recipients of interruptions in workflow. Int J Med Inform. 2010, 79(6):e109-15.

[44] Brixey JJ, Robinson DJ, Johnson CW, Johnson TR, Turley JP, Zhang J. A concept analysis of the phenomenon interruption. ANS Adv Nurs Sci. 2007, 30(1):E26-42.

[45] Healey AN, Sevdalis N, Vincent CA. Measuring intra-operative interference from distraction and interruption observed in the operating theatre. Ergonomics. 2006, 49(5-6):589-604. 
[46] Sevdalis N, Forrest D, Undre S, Darzi A, Vincent C. Annoyances, disruptions, and interruptions in surgery: the Disruptions in Surgery Index (DiSI). World J Surg. 2008, 32(8):1643-50.

[47] Patterson ES, Roth EM, Woods DD, Chow R, Gomes JO. Handoff strategies in settings with high consequences for failure: lessons for health care operations. Int J Qual Health Care. 2004, 16(2):125-32.

[48] Martin JS, Ummenhofer W, Manser T, Spirig R. Interprofessional collaboration among nurses and physicians: making a difference in patient outcome. Swiss Med Wkly. 2010, 140:w13062. 


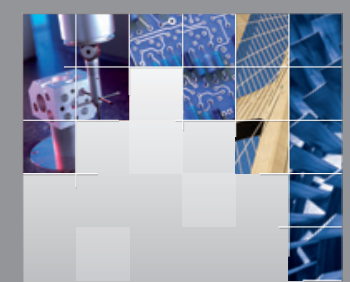

\section{Enfincering}
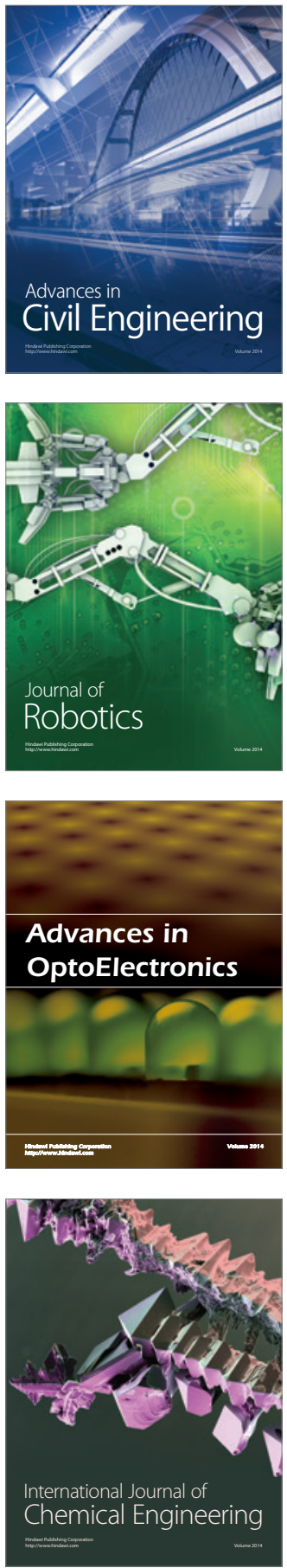

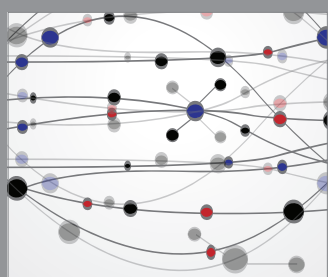

The Scientific World Journal

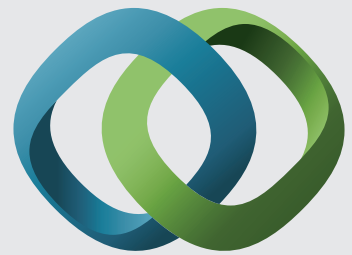

\section{Hindawi}

Submit your manuscripts at

http://www.hindawi.com
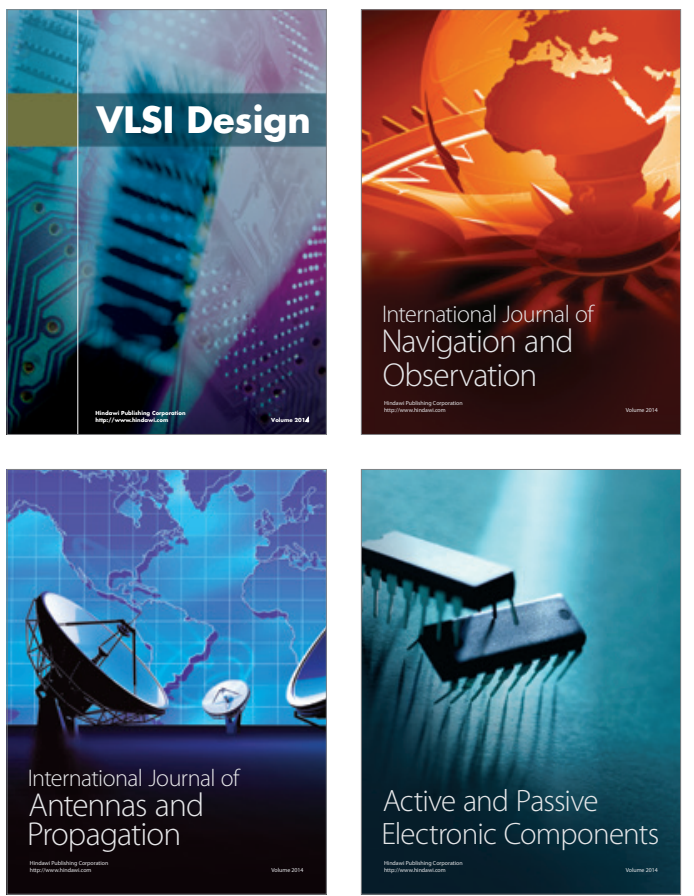
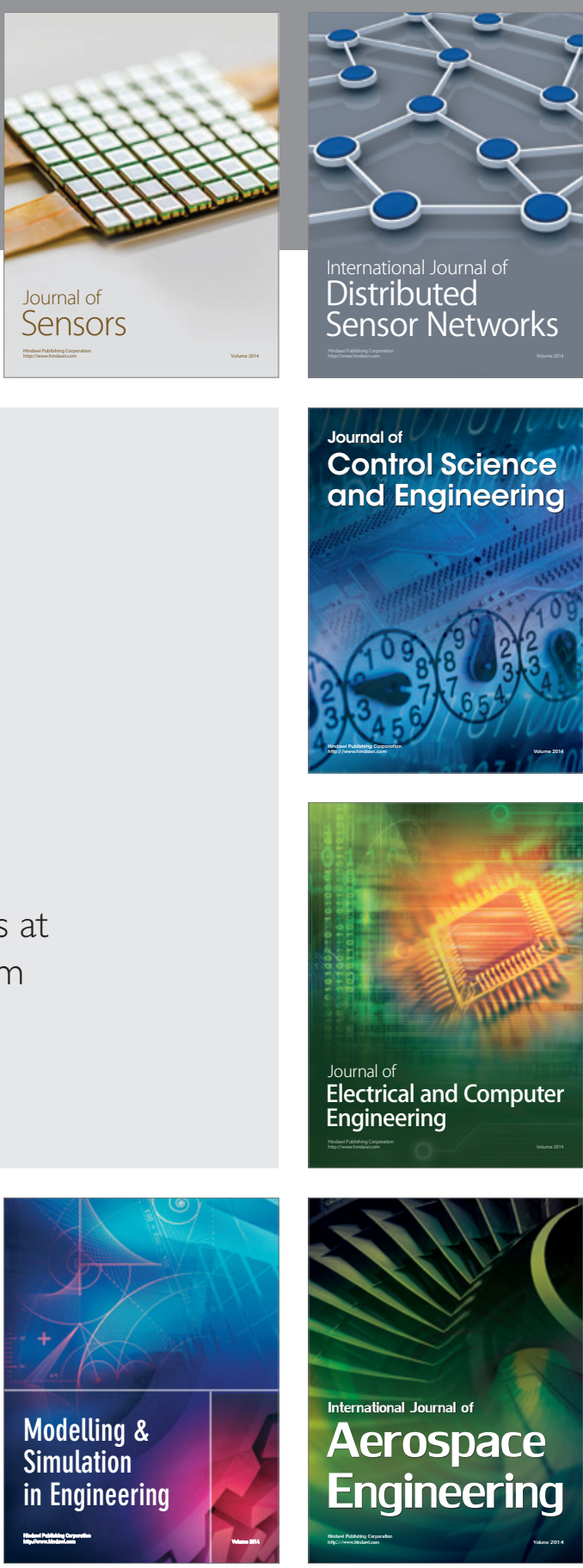

International Journal of

Distributed

Sensor Networks

Journal of

Control Science

and Engineering
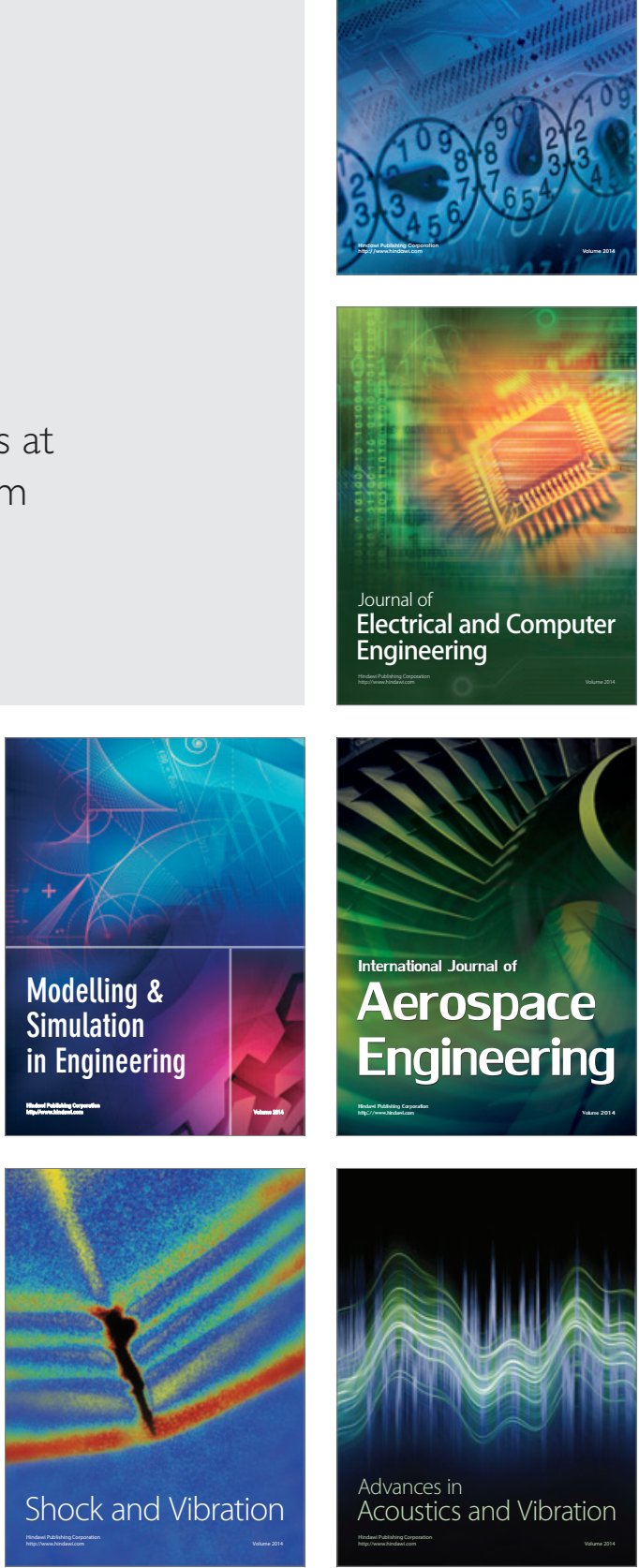